\title{
ENIGMATIC X-RAY MAGNETIC CIRCULAR DICHROISM IN GREIGITE $\left(\mathrm{Fe}_{3} \mathrm{~S}_{4}\right)$
}

\author{
LIAO $\mathrm{CHANG}^{\S}$ \\ National Oceanography Centre, University of Southampton, European Way, Southampton SO14 3ZH, U.K. \\ RICHARD A.D. PATTRICK* \\ School of Earth, Atmospheric and Environmental Sciences and Williamson Research Centre for Molecular Environmental \\ Science, University of Manchester, Manchester M13 9PL, U.K.
}

\section{GERRIT VAN DER LAAN ${ }^{\dagger}$}

School of Earth, Atmospheric and Environmental Sciences and Williamson Research Centre for Molecular Environmental Science, University of Manchester, Manchester M13 9PL, U.K., and Diamond Light Source, Chilton, Didcot OX11 ODE, U.K.

\author{
VICTORIA S. COKER \\ School of Earth, Atmospheric and Environmental Sciences and Williamson Research Centre for Molecular Environmental \\ Science, University of Manchester, Manchester M13 9PL, U.K.
}

ANDREW P. ROBERTS**

National Oceanography Centre, University of Southampton, European Way, Southampton SO14 3ZH, U.K.

\begin{abstract}
Greigite $\left(\mathrm{Fe}_{3} \mathrm{~S}_{4}\right)$, a widely occurring iron thiospinel, was investigated using soft X-ray absorption spectroscopy (XAS) and $\mathrm{X}$-ray magnetic circular dichroism (XMCD). XAS and XMCD spectra were recorded at the $\mathrm{Fe} L_{2,3}$ edges for pure synthetic and natural greigite samples. At the $\mathrm{Fe} L_{3}$ edge, the XAS spectra reveal two main absorption peaks at 707.2 and $708.6 \mathrm{eV}$, which are interpreted to originate from greigite and an oxidized surface layer on greigite crystals. The XMCD spectra, which are dominated by a greigite signal, contain three peaks at 705.3,706.2, and $707.7 \mathrm{eV}$, all with the same sign. The expectation is that the spectrum would have two negative peaks representing $\mathrm{Fe}^{2+}$ and $\mathrm{Fe}^{3+}$ in octahedral coordination, and a positive peak representing $\mathrm{Fe}^{3+}$ in tetrahedral coordination, as found in stoichiometric magnetite $\left(\mathrm{Fe}_{3} \mathrm{O}_{4}\right)$. A reasonable fit of the XMCD data can be achieved without the tetrahedral Fe component, which contradicts magnetic structural information provided by neutron diffraction analysis, and uses unreasonable parameters. The conundrum between theory and experimental data may be caused by the strong covalent effect in sulfides, which causes broadening of the hybridized XMCD peaks and also indicates that multiplet calculations cannot fully predict the properties of greigite. Our results indicate covalent $3 d$ states in greigite, which can destroy the half-metallicity that is present in magnetite. Our measurements represent the best available XAS and XMCD spectra for greigite, but further experimental and modeling information are needed to explain the observed XMCD spectra and to understand what it represents in terms of electronic and magnetic structure. This is important because greigite widely contributes to the magnetic properties of sedimentary rocks.
\end{abstract}

Keywords: greigite, XMCD, XAS, electronic structure, magnetism

$\S$ Corresponding author. Present address: Paleomagnetic Laboratory 'Fort Hoofddijk', Institute of Earth Sciences, Utrecht University, Budapestlaan 17, 3584 CD Utrecht, The Netherlands. E-mail address: L.Chang@uu.nl

E-mail address: richard.pattrick@manchester.ac.uk

E-mail address: gerrit.vanderlaan@diamond.ac.uk

* E-mail address: vicky.coker@manchester.ac.uk

** Present address: Research School of Earth Sciences, The Australian National University, Canberra, ACT 0200, Australia. E-mail address: andrew.roberts@ anu.edu.au 


\section{INTRODUCTION}

Greigite $\left(\mathrm{Fe}_{3} \mathrm{~S}_{4}\right)$ is an iron thiospinel (where oxygen is replaced by sulfur) mineral that shares a similar crystallographic and magnetic structure (e.g., Skinner et al. 1964, Coey et al. 1970, Chang et al. 2009a) with magnetite $\left(\mathrm{Fe}_{3} \mathrm{O}_{4}\right)$, where the difference in covalence of iron with sulfur and oxygen leads to different properties (e.g., Spender et al. 1972, Roberts 1995, Dekkers \& Schoonen 1996, Chang et al. 2008, Roberts et al. 2011). Greigite has been widely identified in natural environments. It commonly forms in sulfate-reducing diagenetic sedimentary environments, hydrothermal ore deposits, and other hydrothermal environments. It is a strongly magnetic mineral that is often the main carrier of paleomagnetic and paleoenvironmental information through remanent magnetization and environmental magnetic proxies in such settings (e.g., Roberts et al. 2011). Greigite also forms as a biomineral that is produced by a range of organisms, such as magnetotactic bacteria (e.g., Konhauser 1998, Bazylinski \& Frankel 2004) and a gastropod found in deep-sea hydrothermal vents (Warén et al. 2003).

Band structure calculations suggest that greigite is a semi-metal (Devey et al. 2009), although spinresolved experiments would be required to confirm this interpretation. This may place greigite within a select group of materials with potential spintronics applications ( $c f$. Wolf et al. 2001). Another recent electronic structure calculation indicates that greigite is a normal metal, in contrast to halfmetallic magnetite (Zhang et $a l$. in press). They found that the existence of sheets of the Fermi surface depends on the direction of the magnetization in greigite, which could enable spinorbitronics. Despite the widespread terrestrial occurrence and importance of greigite, its mineralogical properties are relatively poorly constrained. Pure synthetic greigite has only recently been produced in the laboratory (Tang et al. 2007, Chang et al. 2008). The synthetic greigite samples have been used to determine the fundamental structural and magnetic properties of greigite (Chang et al. 2008, 2009a). Neutron diffraction and Rietveld profile analysis of these samples indicate a collinear ferrimagnetic structure of greigite with lower spin moments for iron compared to studies of magnetite (Chang et al. 2009a). This firmly established its crystallographic and magnetic structures. However, its electronic structure (i.e., valence and electron correlation) is less well understood, and details of the site distribution of $\mathrm{Fe}^{2+}$ and $\mathrm{Fe}^{3+}$ ions in greigite are not defined. Neutrons can only probe the average magnetic moments of $\mathrm{Fe}$ ions in the crystal lattice. Synchrotron-based $\mathrm{X}$-ray spectroscopic techniques can provide quantitative information for cation site occupations in ferri- and ferromagnetic minerals and have been used successfully for magnetite (Pattrick et al. 2002, Morrall et al. 2003), natural ferrite spinels (Pattrick et al. 2002, Pearce et al.
2006), and bio-spinels (Coker et al. 2007, 2008). We report X-ray absorption spectroscopic (XAS) and X-ray magnetic circular dichroism (XMCD) measurements for pure greigite samples to investigate its electronic and magnetic structure.

\section{SAMPLES}

The pure synthetic greigite samples used for the synchrotron experiments are the same as those used for previous neutron scattering experiments (Chang et al. 2009a). They were prepared by hydrothermally reacting ferric chloride $\left(\mathrm{FeCl}_{3} \cdot 6 \mathrm{H}_{2} \mathrm{O}\right)$ with thiourea $\left(\mathrm{CH}_{4} \mathrm{~N}_{2} \mathrm{~S}\right)$ and formic acid $(\mathrm{HCOOH})$ at $170{ }^{\circ} \mathrm{C}$ for eight hours (Tang et al. 2007, Chang et al. 2008). The samples have been confirmed to be single-phase greigite that occurs as large polycrystalline grains (in the $10 \mu \mathrm{m}$ diameter range) (Chang et al. 2008). After synthesis, the greigite samples were placed in small glass sample containers and stored in a desiccator to prevent wet oxidation. Measurements were also made for the purest natural greigite samples in our collection from Italy (Florindo \& Sagnotti 1995, van Dongen et al. 2007) and Taiwan (Jiang et al. 2001). Greigite is the only magnetic phase in these natural greigite samples. The greigite concentration by mass exceeds $30 \%$ as inferred from their saturation magnetization values. The impurities mainly consist of paramagnetic pyrite $\left(\mathrm{FeS}_{2}\right)$ and organic material. Detailed information about the studied greigite samples is provided by Chang et al. (2008, 2009a,b).

\section{MethodS}

In X-ray absorption, core electrons are excited into an empty $3 d$ state above the Fermi level and thus XAS provides element specific information about the coordination environment of the atoms and their electronic state. XMCD is the difference spectrum of two X-ray absorption spectra taken with opposite magnetic fields and measured with circularly polarized X-rays. The resulting $\mathrm{Fe} L_{2,3}$ XMCD spectra provide information about the local electronic structure of the absorbing atom through excitation of $2 p$ core electrons by electricdipole transitions into localized unoccupied $3 d$ states (van der Laan \& Thole 1991). XMCD is a unique element- and site-specific probe of the magnetism for ferri- and ferromagnetic minerals (Pattrick et al. 2002, Pearce et al. 2006).

XAS and XMCD spectra were measured at the Advanced Light Source (ALS) at the Lawrence Berkeley National Laboratory, California, USA. The pure synthetic and natural greigite samples were ground in an anaerobic cabinet and mounted onto conducting carbon tape attached onto a copper sample holder. Surficially oxidized material was cut from the natural greigite-bearing sedimentary rocks prior to sample grinding and mounting. Samples were maintained in 
an anaerobic environment during sample loading into the vacuum chamber, using a specially designed holder, to avoid oxidation of newly exposed mineral surfaces after grinding.

The measurements were made at the magnetic spectroscopy beamline 4.0.2, where the $\mathrm{X}$-ray beam is monochromatized by a variable-included-angle planegrating monochromator, resulting in an instrumental energy resolution of $\sim 0.1 \mathrm{eV}$. The incident and absorbed photon flux were monitored in total-electron-yield (TEY) mode. XAS spectra were acquired with circularly polarized photons in an applied magnetic field of \pm 0.6 $\mathrm{T}$, which was reversed at every energy point, providing two polarized XAS spectra. The direction of the X-ray beam is along the magnetization direction. The two polarized XAS spectra were normalized to the incident beam intensity and their difference gives the XMCD (Pattrick et al. 2002, Pearce et al. 2006).

The calculated XMCD curves for each Fe site used in the fitting were first convoluted using a Gaussian line shape to account for instrumental peak broadening. In these atomic multiplet calculations (van der Laan \& Thole 1991, van der Laan 2006), the Hartree-Fock Slater integrals for the $3 d-3 d$ and $2 p-3 d$ Coulomb and exchange interactions were scaled to $70 \%$ and $80 \%$, respectively. The calculated XMCD spectra were fitted to the $L_{3}$ edge peaks, which have been shown to give meaningful results (Pattrick et al. 2002).

\section{RESULTS}

XAS and XMCD spectra for a synthetic and a natural greigite sample are shown in Figure 1. The XAS spectra contain two main absorption peaks at 707.2 and $708.6 \mathrm{eV}$ at the $\mathrm{Fe} L_{3}$ edge, when calibrated to the main XAS peak for magnetite at $708.8 \mathrm{eV}$ (after Regan et al. 2001) (Fig. 1a). Comparison of a representative greigite XAS spectrum with those for magnetite $\left(\mathrm{Fe}^{2+}: \mathrm{Fe}^{3+}=\right.$ 1:2) and goethite (all $\mathrm{Fe}^{3+}$ ) reveals that the main XAS peak in greigite is shifted to lower energies $\sim 0.2 \mathrm{eV}$ (Fig. 2a). In addition, the shape of the peak differs from that of the mixed $\mathrm{Fe}$ valence in magnetite and that of the $\mathrm{Fe}^{3+}$-bearing phase in goethite in that it has a far greater intensity on the lower energy side of the $L_{3}$ edge at $707.2 \mathrm{eV}$ (Fig. 2a). XMCD spectra derived from the greigite samples have three negative peaks at energies of 705.3, 706.2, and $707.7 \mathrm{eV}$ (Fig. 1b), which contrasts with the XMCD spectra obtained for a standard natural magnetite (Fig. 2b) (Pattrick et al. 2002, Pearce et al. 2006, Coker et al. 2007). In magnetite, the three distinct peaks in the XMCD spectrum correspond to the three main coordination environments of $\mathrm{Fe}$, namely (with increasing energy), negative octahedral $\left(O_{h}\right) \mathrm{Fe}^{2+}$, positive tetrahedral $\left(T_{d}\right) \mathrm{Fe}^{3+}$, and negative $O_{h}$ $\mathrm{Fe}^{3+}$ peaks (Fig. 2b). These peaks are not all seen in the greigite XMCD spectra where the positive component (representing $T_{d} \mathrm{Fe}^{3+}$ in magnetite) is absent (Fig. 2b).

\section{DISCUSSION}

The two main peaks in the Fe $L_{3}$ edge XMCD spectrum for greigite are at 706.2 and $707.7 \mathrm{eV}$, with an energy separation of $1.5 \mathrm{eV}$ (Fig. 1b). These two XMCD peaks do not coincide with the main intensity peaks in the XAS spectra (at 707.2 and $708.6 \mathrm{eV}$ ) (Fig. 1a). Instead, the main negative peaks of the XMCD spectrum coincide with the trough between the two main XAS peaks (Fig. 1; the vertical dotted line is a guide). This indicates that the high-energy component of the XAS spectra is non-magnetic (paramagnetic or antiferromagnetic), which is consistent with the presence of an oxidized Fe-species, such as goethite (Fig. 2a). Although the samples were mounted anaerobically, the crystals were in air prior to that. New surfaces of greigite, exposed during anaerobic grinding, will not have been oxidized, but outer surfaces of the individual synthetic greigite crystals and the natural crystals had plenty of opportunity to interact with $\mathrm{O}_{2}$. Thus, the nonmagnetic species is likely to be an oxidized surficial ('outer') layer on the greigite crystals. The signal of the Fe $L_{2,3}$ XAS in TEY mode decreases exponentially with a probing depth of $\sim 5 \mathrm{~nm}$, so that the spectrum is dominated by the outer layers of the sample. An oxidized layer has been observed surrounding greigite grains using transmission electron microscopy (TEM) in electron energy loss spectroscopy (EELS) by Letard et al. (2005) and Kasama et al. (2006). In these studies, a thin amorphous oxidized surface layer (a few $\mathrm{nm}$ ) was often observed. The shape of the XAS spectra presented here is similar to that reported for greigite by Letard et al. (2005), who attributed the surficial layer to an amorphous oxide with composition close to ferrihydrite or hematite $\left(\alpha-\mathrm{Fe}_{2} \mathrm{O}_{3}\right)$. However, Letard at al. (2005) found that the maxima of the two XMCD peaks occur at the same energies as the XAS maxima for their greigite samples. This suggests that in their greigite samples, the surficial oxide is partially magnetic (e.g., $\gamma-\mathrm{Fe}_{2} \mathrm{O}_{3}$ ), but this requires further investigation. In another brief laboratory report, Hitchcock et al. (2010) presented novel XAS and XMCD spectra recorded from individual greigite magnetosome crystals using scanning transmission X-ray microscopy. Although no clear XMCD signature for greigite could be extracted, their XAS spectra are different from our results in that they observed two peaks at $\sim 708.5$ and $710 \mathrm{eV}$ with a relatively larger intensity of the lower peak. They attribute this to a more reduced nature of their bacterial samples. It should be noted that the substantial peak at lower energy in the goethite XAS spectrum is consistent with calculated spectra (van der Laan \& Kirkman 1992) for $O_{h} \mathrm{Fe}^{3+}\left(\mathrm{d}^{5}\right)$, which contain two peaks with an energy separation of $\sim 1.5 \mathrm{eV}$. In the greigite XAS spectra, the peak at lower energy is at roughly the same position as would be expected for $O_{h} \mathrm{Fe}^{2+}\left(\mathrm{d}^{6}\right)$. Therefore, this peak at lower energy probably contains both 


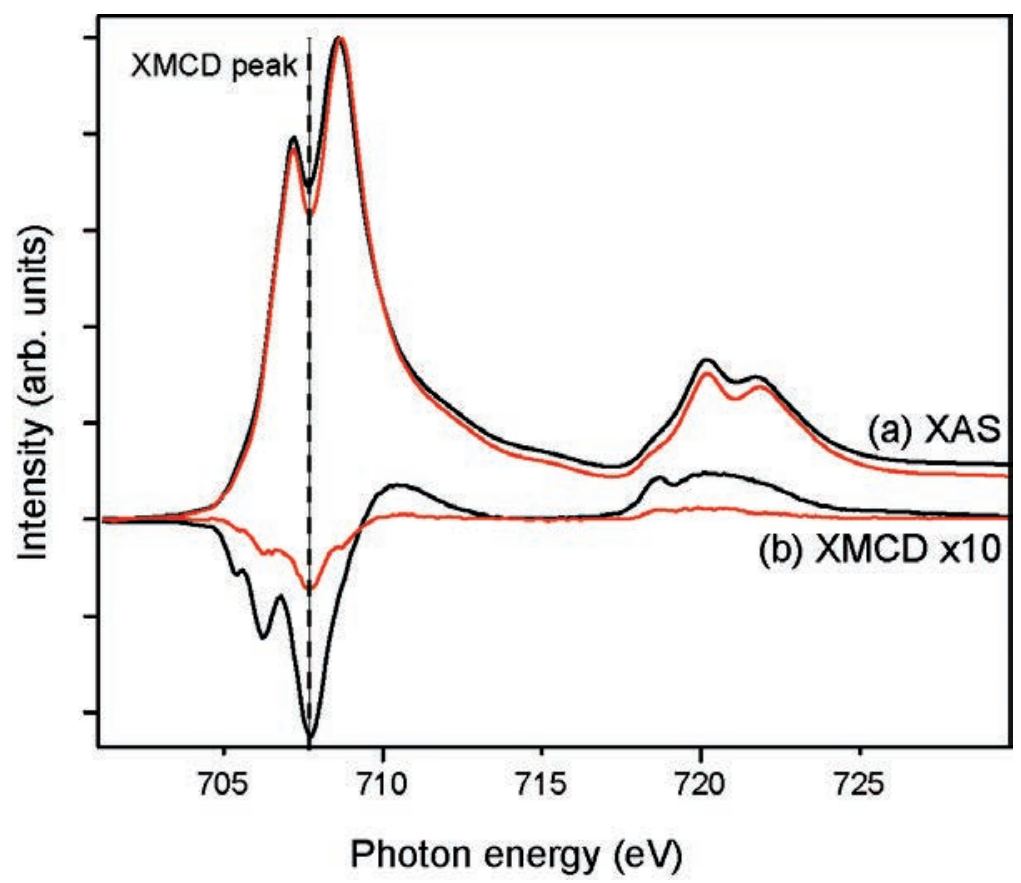

FIG. 1. Fe $L_{2,3} \mathrm{XAS}$ and XMCD spectra for greigite. (a) XAS spectra and (b) corresponding XMCD spectra for synthetic (black) and natural (red) greigite. The XAS spectra were normalized to their maximum peak. The noticeable intensity difference in the corresponding XMCD patterns is because the natural greigite samples contain nonmagnetic iron-bearing materials, such as pyrite and clay minerals, which contribute to the XAS, but not to the XMCD signal. The dotted line indicates that the strong negative $\mathrm{XMCD}$ peak is derived from the trough between the two main XAS peaks, rather than from the high-energy XAS maxima.

$\mathrm{Fe}^{3+}$ and $\mathrm{Fe}^{2+}$. In covalent compounds, the position of this lower energy $\mathrm{Fe}^{3+}$ peak might be shifted, e.g., by the Madelung potential, as seen in $\mathrm{FeS}_{2}$ where the $\mathrm{Fe}$ $L_{3}$ XAS spectrum has a somewhat lower energy than in magnetite (Thole \& van der Laan 1988). The Madelung potential is the electrostatic potential of a single ion in a crystal by approximating the ions by effective point charges. The effective point charges and distances of oxygen in magnetite and sulfur in greigite are different and hence change the electrostatic potential, which shifts the energies of the absorption peaks. This helps to explain some of the observed shift in energies in the XAS spectra.

Apart from a decreased signal, the measured XMCD spectrum is not affected by the non-magnetic oxide layer: it therefore originates from the ferrimagnetic greigite, or from the interface with the surficial oxide layer. However, the observed XMCD spectrum is significantly different from that expected for a ferrimagnetic inverse spinel (e.g., Pattrick et al. 2002), and the contrast with the spectrum for magnetite is striking (Fig. 2b). Neutron diffraction and Mössbauer analyses for greigite (e.g., Coey et al. 1970, Spender et al. 1972, Chang et al. 2008, 2009a) indicate that it has a collinear ferrimagnetic structure similar to that of magnetite. Therefore, the XMCD spectra would be expected to have the same $O_{h} \mathrm{Fe}^{2+}, O_{h} \mathrm{Fe}^{3+}$, and $T_{d} \mathrm{Fe}^{3+}$ components observed in stoichiometric magnetite (e.g., Pattrick et al. 2002, Morrall et al. 2003, Pearce et al. 2006, Coker et al. 2007, Carvallo et al. 2008) (Fig. 2b). Calculations of the expected XMCD contributions for the three Fe sites in greigite (Fig. 3a) indicate that the maxima in the XMCD spectra are coincident with the maxima of the XAS spectra. Iron in greigite has a fairly high spin and, given the larger crystal field in sulfides compared to oxides (Burns 1993), the crystal field values used for the sites were chosen as d $\mathrm{d}^{5} O_{h}=2.5 \mathrm{eV}, \mathrm{d}^{5} T_{d}=1.1 \mathrm{eV}$, and $\mathrm{d}^{6} O_{h}=1.6 \mathrm{eV}$; larger values would result in low-spin configurations. Using these values to fit the measured data, a reasonable agreement between the calculation and the experiment is obtained by including only the $\mathrm{d}^{5}$ $O_{h}$ and $\mathrm{d}^{6} O_{h}$ peaks while omitting the $\mathrm{d}^{5} T_{d}$ one (Fig. $3 b)$. Letard et al. (2005) produced a similar greigite spectrum to that seen here (but at a different energy 
FIG. 2. Comparison of XAS and XMCD spectra for greigite, magnetite and goethite. (a) Fe $L_{2,3} \mathrm{XAS}$ and (b) corresponding XMCD spectra for synthetic greigite (black) and natural magnetite (red) (Pearce et al. 2006) compared to a goethite (blue) XAS spectrum. The XAS spectra were normalized to their maximum peak.
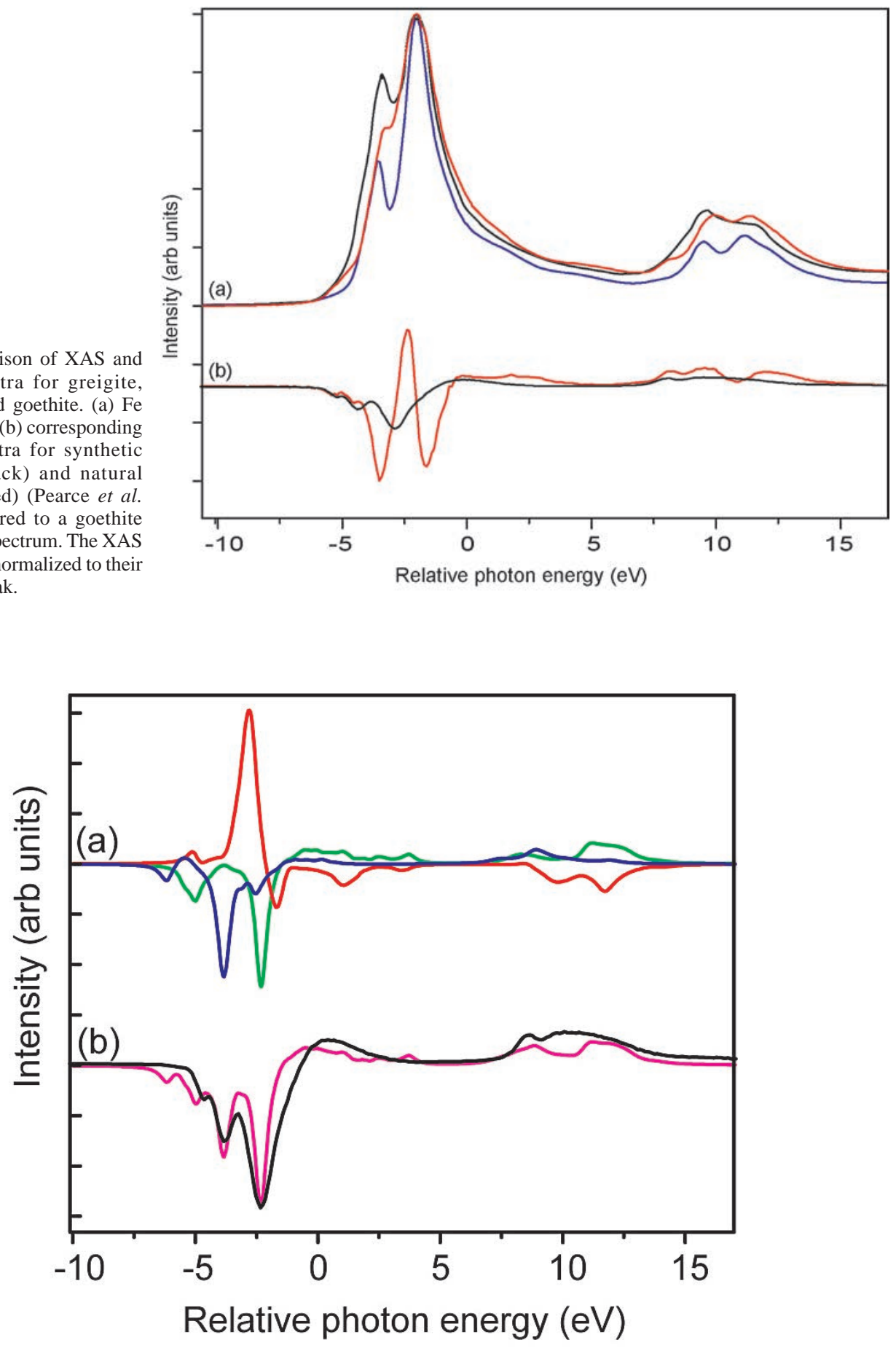

FIG. 3. Comparison of calculated and measured XMCD spectra for greigite. (a) Calculated spectra for $O_{h} \mathrm{Fe}^{2+}$ (blue), $T_{d} \mathrm{Fe}^{3+}$ (red), and $O_{h} \mathrm{Fe}^{3+}$ (green). (b) Experimental XMCD spectra for synthetic greigite (black) compared to the sum of the calculations from (a) for $O_{h} \mathrm{Fe}^{2+}$ and $O_{h} \mathrm{Fe}^{3+}$ (magenta). 
position with respect to the XAS) and suggested that the difference in the XMCD spectra between greigite and magnetite is attributable to the possible presence of $\mathrm{Fe}$ vacancies in greigite, similar to the case for maghemite $\left(\gamma-\mathrm{Fe}_{2} \mathrm{O}_{3}\right)$. However, this contradicts the neutron diffraction study on greigite. Rietveld profile analysis of the neutron diffraction pattern, which included parameters for partial occupancy of the Fe sites, indicates that the greigite samples studied here do not have a significant vacancy concentration (Chang et al. 2009a). Similarly, Qian et al. (1999) determined the composition of their hydrothermal synthetic greigite and found that the greigite samples are nearly stoichiometric $\left(\mathrm{Fe}_{2.994} \mathrm{~S}_{4}\right)$.

If the measured XAS spectra (Fig. 1a) contain contributions from $\mathrm{Fe}_{3} \mathrm{~S}_{4}$ and $\mathrm{Fe}$-oxide, the XMCD results may also be explained if the spectrum is derived from mainly $O_{h} \mathrm{Fe}^{2+}$ and the $T_{d} \mathrm{Fe}^{3+}$ and $O_{h} \mathrm{Fe}^{3+}$ signals largely cancel each other. The $T_{d} \mathrm{Fe}^{3+}$ and $O_{h} \mathrm{Fe}^{3+}$ peaks can be at the same energy position, and if they have the same but opposite magnetic moment the high-energy part of the XMCD spectrum disappears. This explanation would account for the magnetic moments at all three different sites, but fitting the measured XMCD spectrum by summing the three individual calculated spectra does not give a convincing comparison with experiments (Fig. 3b). Part of the problem is that the strong covalent sulfur bindings complicate the XMCD properties of greigite. A relatively high degree of covalency in sulfides compared to oxides of similar structure is well known (e.g., Coey et al. 1970, Spender et al. 1972, Devey et al. 2009), which is also supported by the measured lower saturation magnetization for greigite $\left(3.13 \mu_{\mathrm{B}}\right.$ /formula unit at room temperature) compared to magnetite (Chang et al. 2008). Neutron powder diffraction results also indicate lower magnetic moments of iron (both $\mathrm{Fe}^{2+}$ and $\mathrm{Fe}^{3+}$ in the two sublattices) in greigite (Chang et al. 2009a). For example, the magnetic moments of the iron in the three different sites of $\mathrm{Fe}_{3} \mathrm{~S}_{4}$ are $+2.99 \mu_{\mathrm{B}},-3.17 \mu_{\mathrm{B}}$, and $-3.17 \mu_{\mathrm{B}}$, which gives a net moment of $3.35 \mu_{\mathrm{B}}$ at $100 \mathrm{~K}$ (Chang et al. 2009a). Compared to $\mathrm{Fe}_{3} \mathrm{O}_{4}$ at $130 \mathrm{~K}$, the magnetic moments are $+4.20 \mu_{\mathrm{B}},-3.97 \mu_{\mathrm{B}}$, and $-3.97 \mu_{\mathrm{B}}$, which gives a net moment of $3.74 \mu_{\mathrm{B}}$ (Wright et al. 2002). The strong covalent sulfur bindings in greigite mean that it cannot be well constrained using multiplet calculations and that the hybridized peaks might also be broadened in some way. Our results show covalent $3 d$ states in greigite. This covalency can possibly destroy the halfmetallicity that is present in magnetite. More XAS and XMCD experiments and theoretical modeling are needed to constrain the electronic structure of greigite.

\section{CONCLUSIONS}

The XAS spectra at the $\mathrm{Fe} L_{3}$ edge for synthetic and natural greigite samples have two absorption peaks at 707.2 and $708.6 \mathrm{eV}$, which are probably due to absorptions from greigite and the thin oxidized layer surrounding the greigite crystals. The low- and highenergy XAS peaks are interpreted to represent dominant absorption from $\mathrm{Fe}^{2+}$ and $\mathrm{Fe}^{3+}$ in greigite and oxide $\mathrm{Fe}$-species in the shell of greigite grains, respectively. The XMCD spectra, which should represent a dominant greigite signal, have three negative peaks at 705.3, 706.2, and $707.7 \mathrm{eV}$. This is not expected, considering its ferrimagnetic structure, and is also significantly different from that of stoichiometric magnetite. A reasonable XMCD fit can be achieved without the $T_{d} \mathrm{Fe}^{3+}$ component. However, this is not consistent with neutron diffraction results from the same greigite samples, which indicate an almost full site occupation of Fe in greigite. This discrepancy may be caused by the strong covalent sulfur binding in greigite, which means that multiplet calculations cannot be well performed for greigite and that the hybridized XMCD peaks may also be broader. Nevertheless, our results represent the best available XAS and XMCD spectra for greigite and provide valuable information on the poorly constrained mineralogical behavior of this increasingly important magnetic mineral.

\section{ACKNOWLEDGEMENTS}

We thank the Advanced Light Source (ALS) for access to beamline 4.0.2. The ALS is supported by the Director, Office of Science, Office of Basic Energy Sciences, of the U.S. Department of Energy under Contract No. DE-AC02-05CH11231. We are grateful to beamline scientist Elke Arenholz for technical assistance and to Carolyn Pearce and Neil Telling for their assistance with measurements. We are grateful to two anonymous reviewers and the Associate Editor Yuanming Pan for comments that improved this paper. We thank Editor Lee Groat for editorial handling. This work contributes to the objectives of NERC grant NE/ G003319/1 to APR and an EPSRC grant awarded to $\mathrm{RP}$ and VC.

\section{REFERENCES CITED}

Bazylinski, D.A. \& Frankel, R.B. (2004) Magnetosome formation in prokaryotes. Nature Reviews Microbiology 2, 217-230.

Burns, R.G. (1993) Mineralogical Applications of Crystal Field Theory (Second Edition). Cambridge Topics in Mineral Physics and Chemistry, Cambridge University Press, Cambridge.

Carvallo, C., Sainctavit, P., Arrio, M.-A., Menguy, N., Wang, Y., Ona-Nguema, G., \& Brice-Profeta, S. (2008) Biogenic vs. abiogenic magnetite nanoparticles: A XMCD study. American Mineralogist 93, 880-885.

Chang, L., Roberts, A.P., Tang, Y., Rainford, B.D., Muxworthy, A.R., \& Chen, Q. (2008) Fundamental magnetic parameters from pure synthetic greigite $\left(\mathrm{Fe}_{3} \mathrm{~S}_{4}\right)$. Journal of Geophysical Research 113, B06104. 
Chang, L., Rainford, B.D., Stewart, J.R., Ritter, C., Roberts, A.P., Tang, Y., \& Chen, Q. (2009a) Magnetic structure of greigite $\left(\mathrm{Fe}_{3} \mathrm{~S}_{4}\right)$ probed by neutron powder diffraction and polarized neutron diffraction. Journal of Geophysical Research 114, B07101.

Chang, L., Roberts, A.P., Rowan, C.J., Tang, Y., Pruner, P., Chen, Q., \& Horng, C.S. (2009b) Low-temperature magnetic properties of greigite $\left(\mathrm{Fe}_{3} \mathrm{~S}_{4}\right)$. Geochemistry, Geophysics, Geosystems 10, Q01Y04.

Coey, J.M.D., Spender, M.R., \& Morrish, A.H. (1970) The magnetic structure of the spinel, $\mathrm{Fe}_{3} \mathrm{~S}_{4}$. Solid State Communications 8, 1605-1608.

Coker, V.S., Pearce, C.I., Lang, C., van der Laan, G., Pattrick, R.A.D., Telling, N.D., Schüler, D., Arenholz, E., \& Lloyd, J.R. (2007) Cation site occupancy of biogenic magnetite compared to polygenic ferrite spinels determined by X-ray magnetic circular dichroism. European Journal of Mineralogy 19, 707-716.

Coker, V.S., Pearce, C.I., Pattrick, R.A.D., van der Laan, G., Telling, N.D., Charnock, J., Arenholz, E., \& Lloyd, J.R. (2008) Probing the site occupancies of Co-, Ni-, and Mnsubstituted biogenic magnetite using XAS and XMCD. American Mineralogist 93, 1119-1132.

Dekkers, M.J. \& Schoonen, M.A.A. (1996) Magnetic properties of hydrothermally synthesized greigite-I. Rock magnetic parameters at room temperature. Geophysical Journal International 126, 360-368.

Devey, A.J., Grau-Crespo, R., \& de Leeuw, N.H. (2009) Electronic and magnetic structure of $\mathrm{Fe}_{3} \mathrm{~S}_{4}$ : GGA + U investigation. Physical Review B 79, 195126.

Florindo, F. \& Sagnotti, L. (1995) Palaeomagnetism and rock magnetism in the upper Pliocene Valle Ricca (Rome, Italy) section. Geophysical Journal International 123, 340-354.

Hitchcock, A.P., Lam, K.P., Kalirai, S., Bazylinski, D.A., Lins, U., \& Wang, J. (2010) Bacterial magnetism studied by Scanning Transmission X-ray Microscopy. Canadian Light Source Research Report 2010, 40-41.

Jiang, W.T., Horng, C.S., Roberts, A.P., \& Peacor, D.R. (2001) Contradictory magnetic polarities in sediments and variable timing of neoformation of authigenic greigite. Earth and Planetary Science Letters 193, 1-12.

Kasama, T., Pósfai, M., Chong, R.K.K., Finlayson, A.P., Buseck, P.R., Frankel, R.B., \& Dunin-Borkowski, R.E. (2006) Magnetic properties, microstructure, composition, and morphology of greigite nanocrystals in magnetotactic bacteria from electron holography and tomography. American Mineralogist 91, 1216-1229.

Konhauser, K.O. (1998) Diversity of bacterial iron mineralization. Earth-Science Reviews 43, 91-121.

Letard, I., Sainctavit, P., Menguy, N., Valet, J.-P., Isambert, A., Dekkers, M., \& Gloter, A. (2005) Mineralogy of greigite $\mathrm{Fe}_{3} \mathrm{~S}_{4}$. Physica Scripta T115, 489-491.
Morrall, P., Schedin, F., Case, G.S., Thomas, M.F., Dudzik, E., van der Laan, G., \& Thornton, G. (2003) Stoichiometry of $\mathrm{Fe}_{3-\delta} \mathrm{O}_{4}(111)$ ultrathin films on $\mathrm{Pt}(111)$. Physical Review $B$ 67, 214408-1/7.

Pattrick, R.A.D., van der Laan, G., Henderson, C.M.B., Kuiper, P., Dudzik, E., \& Vaughan, D.J. (2002) Cation site occupancy in spinel ferrites studied by X-ray magnetic circular dichroism: developing a method for mineralogists. European Journal of Mineralogy 14, 1095-1102.

Pearce, C.I., Henderson, C.M.B., Pattrick, R.A.D., van der Laan, G., \& Vaughan, D.J. (2006) Direct determination of cation site occupancies in natural ferrite spinels by $L_{2,3}$ $\mathrm{X}$-ray absorption spectroscopy and X-ray magnetic circular dichroism. American Mineralogist 91, 880-893.

Qian, X.F., Zhang, X.M., Wang, C., Xie, Y., Wang, W.Z., \& Qian, Y.T. (1999) The preparation and phase transition of nanocrystalline iron sulfides via toluene-thermal process. Materials Science and Engineering 64, 170-173.

Regan, T.J., Ohldag, H., Stamm, C., Nolting, F., Luning, J., Stohr, J., \& White, R.L. (2001) Chemical effects at metal/ oxide interfaces studied by x-ray-absorption spectroscopy. Physical Review B 64, 214422-1/11.

Roberts, A.P. (1995) Magnetic properties of sedimentary greigite $\left(\mathrm{Fe}_{3} \mathrm{~S}_{4}\right)$. Earth and Planetary Science Letters 134, 227-236.

Roberts, A.P., Chang, L., Rowan, C.J., Horng, C.-S., \& Florindo, F. (2011) Magnetic properties of sedimentary greigite $\left(\mathrm{Fe}_{3} \mathrm{~S}_{4}\right)$ : An update. Reviews of Geophysics 49 , RG1002.

Skinner, B.J., Erd, R.C., \& Grimaldi, F.S. (1964) Greigite, the thiospinel of iron; A new mineral. American Mineralogist 49, 543-555.

Spender, M.R., Coey, J.M.D., \& Morrish, A.H. (1972) The magnetic properties and Mössbauer spectra of synthetic samples of $\mathrm{Fe}_{3} \mathrm{~S}_{4}$. Canadian Journal of Physics 50, 23132326 .

Tang, Y., Chen, Q.W., Xiong, Y., \& Li, Y. (2007) Magnetic field-induced increase in conversion rate of $\mathrm{Fe}_{3} \mathrm{~S}_{4}$ to $\mathrm{FeS}_{2}$. Chinese Journal of Inorganic Chemistry 23, 941-947.

Thole, B.T. \& van der Laan, G. (1988) Branching ratio in X-ray absorption spectroscopy. Physical Review B 38, 3158-3171.

van der Laan, G. \& Thole, B.T. (1991) Strong magnetic X-ray dichroism in $2 p$ absorption spectra of $3 d$ transition metal ions. Physical Review B 43, 13401-13411.

van der Laan, G. \& Kirkman, I.W. (1992) The 2p absorption spectra of $3 \mathrm{~d}$ transition metal compounds in tetrahedral and octahedral symmetry. Journal of Physics: Condensed Matter 4, 4189-4204.

van der Laan, G. (2006) Hitchhiker's Guide to Multiplet Calculations. Lecture Notes in Physics 697, 143-199. 
van Dongen, B.E., Roberts, A.P., Schouten, S., Jiang, W.T., Florindo, F., \& Pancost, R.D. (2007) Formation of iron sulfide nodules during anaerobic oxidation of methane. Geochimica et Cosmochimica Acta 71, 5155-5167.

Wáren, A., Bengtson, S., Goffredi, S.K., \& Van Dover, C.L. (2003) A hot-vent gastropod with iron sulfide dermal schlerites. Science 302, 1007.

Wolf, S.A., Awschalom, D.D., Buhrman, R.A., Daughton, J.M., von Molnár, S., Roukes, M.L., Chtchelkanova, A.Y., \& Treger, D.M. (2001) Spintronics: a spin-based electronics vision for the future. Science 294, 1488-1495.
Wright, J.P., Attfield, J.P., \& Radaelli, P.G. (2002) Charge ordered structure of magnetite below the Verwey transition. Physical Review B 66, 214422(14).

Zhang, B., de Wijs, G.A., \& de Groot, R.A. (in press) Switchable Fermi surface sheets in greigite. Physical Review $B$.

Received January 24, 2012, revised manuscript accepted June 25, 2012. 